\title{
Skinfold Thickness Analysis
}

National Cancer Institute

\section{Source}

National Cancer Institute. Skinfold Thickness Analysis. NCI Thesaurus. Code C77537.

Techniques for estimating body fat whereby a pinch of skin is precisely measured by calipers at several standardized points on the body to determine the subcutaneous fat layer thickness. These measurements are converted to an estimated body fat percentage by an equation. 